\title{
Pleural Mesothelioma Instigates Tumor-Associated Fibroblasts To Promote Progression via a Malignant Cytokine Network
}

\author{
Qi Li, ${ }^{\star \dagger}$ Wei Wang, ${ }^{\star \ddagger}$ Tadaaki Yamada, ${ }^{\text {* }}$ \\ Kunio Matsumoto, ${ }^{\S}$ Katsuya Sakai, $\$$ \\ Yoshimi Bando," Hisanori Uehara," \\ Yasuhiko Nishioka, ** Saburo Sone, ** \\ Shotaro Iwakiri, ${ }^{+\dagger}$ Kazumi Itoi, ${ }^{+\dagger}$ Teruhiro Utsugi, ${ }^{\neq+}$ \\ Kazuo Yasumoto, ${ }^{*}$ and Seiji Yano* \\ From the Divisions of Medical Oncology* and Tumor Dynamics \\ and Regulation, "Cancer Research Institute, Kanazawa \\ University, Kanazawa, Japan; the Departments of \\ Gastroenterology ${ }^{\dagger}$ and Radiation Oncology, ${ }^{\ddagger}$ Nanfang Hospital, \\ Southern Medical University, Guangzhou, China; the Division of \\ Pathology, "T Tokushima University Hospital, Tokushima, Japan; \\ the Departments of Molecular and Environmental Patbology" \\ and Respiratory Medicine and Rheumatology, ** Institute of \\ Health Biosciences, University of Tokushima Graduate School, \\ Tokushima, Japan; the Department of Respiratory Surgery, ${ }^{\text {t+ }}$ \\ Hyogo Prefectural Amagasaki Hospital, Amagasaki, Japan; and \\ the Taibo Pharmaceutical Company, ${ }^{\neq}$Hanno, Japan
}

The tumor microenvironment is crucial to the progression of various malignancies. Malignant pleural mesothelioma (MPM), which originates from the pleura, grows aggressively in the thoracic cavity. Here we describe an orthotopic implantation SCID mouse model of MPM and demonstrate that $\alpha$-SMA-positive fibroblastlike cells accumulate in the tumors produced by the human MPM cell lines MSTO-211H and Y-Meso-14. We assessed the interaction between MPM cells and their microenvironments, focusing on tumor-associated fibroblasts. MSTO-211H and Y-Meso-14 cells produced fibroblast growth factor-2 (FGF-2) and/or platelet-derived growth factor-AA (PDGF-AA); they also enhanced growth, migration, and production of hepatocyte growth factor (HGF) by human lung fibroblast MRC-5 cells. MRC-5 cells stimulated HGF-mediated growth and migration of MSTO-211H and Y-Meso-14 cells in an in vitro coculture system. In the orthotopic model, tumor formation by MSTO-211H and Y-Meso-14 cells was significantly inhibited by TSU-68, an inhibitor of FGF, VEGF, and PDGF receptors; imatinib, an inhibitor of PDGF receptors; and NK4, an antagonist of HGF. Histological analyses of clinical specimens from 51 MPM patients revealed considerable tumor-associated fibroblasts infiltration and expression of HGF, together with FGF-2 or PDGF-AA, in tumors. These findings indicate that MPM instigates tumor-associated fibroblasts, promoting tumor progression via a malignant cytokine network. Regulation of this cytokine network may be therapeutically useful for controlling MPM. (Am J Pathol 2011, 179:1483-1493; DOI: 10.1016/j.ajpath.2011.05.060)

Malignant pleural mesothelioma (MPM) is a unique form of tumor, the development of which is highly related to asbestos exposure. ${ }^{1}$ Even after bans on asbestos were initiated in the 1970s, MPM remains a serious problem worldwide because of its long latency period (30 to 40 years) and high mortality rate. In the United States, 2000 to 3000 patients die of MPM every year. Deaths from this disease are expected to peak in 2020 to 2025, with more than 250,000 deaths expected to occur in Western Europe and Japan over the next 40 years. ${ }^{2}$ MPM grows aggressively, with dissemination in the thoracic cavity, and frequently produces a malignant pleural effusion. ${ }^{3}$ MPM is rarely diagnosed at an operable stage, and it is refractory to

Supported by the Program for Promotion of Fundamental Studies in Health Sciences of the National Institute of Biomedical Innovation, Grantin-Aid of Cancer Research (21390256 to S.Y. and 17016051 to S.S.), and Scientific Research on Innovative Areas "Integrative Research on Cancer Microenvironment Network" (22112010A01 to S.Y.) from the Ministry of Education, Culture, Sports, Science, and Technology of Japan and a commercial research grant from Taiho Pharmaceutical Company (S.S.).

Accepted for publication May 23, 2011.

Q.L. and W.W. contributed equally to the present work.

Disclosures: T.U. is an employee of Taiho Pharmaceutical Company, and S.S. obtained a commercial research grant from Taiho Pharmaceutical Company.

Supplemental material for this article can be found at http://ajp. amjpathol.org or at doi: 10.1016/j.ajpath.2011.05.060

Address reprint requests to Seiji Yano, M.D., Ph.D., Division of Medical Oncology, Cancer Research Institute, Kanazawa University, Kanazawa, Ishikawa 920-0934, Japan. E-mail: syano@staff.kanazawa-u.ac.jp. 
conventional chemotherapy and radiotherapy. Thus, the prognosis of patients with this disease is extremely poor, with median survival varying between 8 and 14 months after diagnosis, despite the recent development of a chemotherapy regimen combining cisplatin and an antifolate agent such as pemetrexed or raltitrexed. ${ }^{4}$

The tumor microenvironment is crucial for the progression and chemosensitivity of various malignant diseases. ${ }^{5}$ For example, the tumor microenvironment mediates endocrine instigation of indolent metastatic tumor progression via osteopontin. ${ }^{6}$ Moreover, EGFR-TKI resistance may be induced by microenvironmental fibroblasts in epidermal growth factor receptor mutant lung cancer. ${ }^{7}$ Thus, innovative therapies may target the microenvironment. For example, antiangiogenic therapy targeting host endothelial cells and bisphosphonate targeting host osteoclasts have been successfully used to treat several malignant diseases, including colon cancer, ${ }^{8}$ non-small cell lung cancer, ${ }^{9,10}$ and metastatic bone tumors. ${ }^{11}$

In MPM, angiogenesis inhibition using an anti-VEGF antibody targeting endothelial cells can successfully control the progression of MPM cells that produce high concentrations of VEGF. ${ }^{12}$ Tumor-associated fibroblasts (TAFs), also known as cancer-associated fibroblasts, are the major component of tumor microenvironments. ${ }^{13}$ TAFs regulate tumor behavior through several mediators. Although recent studies show that many populations of MPM contain TAFs, ${ }^{14}$ little is known about interactions between TAFs and MPM. We therefore investigated the molecular interaction between MPM and TAFs, using an orthotopic implantation SCID mice model and clinical specimens taken from MPM patients. We show here that MPMs produce fibroblast-growth factor 2 (FGF-2) and platelet-derived growth factor-AA (PDGF-AA), and that these growth factors stimulate TAFs to produce hepatocyte growth factor (HGF), thus promoting tumor progression through a malignant cytokine network.

\section{Materials and Methods}

\section{Cell Lines and Reagents}

We used the human MPM cell lines MSTO-211H, EHMES10, and Y-Meso-14, established from patients with biphasic type MPM. MSTO-211H cells were purchased from the American Type Culture Collection (ATCC, Manassas, VA). EHMES-10 were kindly provided by Dr. Hironobu Hamada (Ehime University, Ehime, Japan) and Y-Meso-14 cells by Dr. Yoshitaka Sekido (Aichi Cancer Center Research Institute, Nagoya, Japan). Cells were cultured in modified Eagle's medium or in RPMI 1640 supplemented with 10\% heat-inactivated fetal bovine serum (FBS) and gentamicin at $37^{\circ} \mathrm{C}$ in a humidified atmosphere of $5 \% \mathrm{CO}_{2}$ in air. The human embryonic lung fibroblast cell line MRC- 5 and the mouse fibroblast cell line 3T3-Swiss were purchased from ATCC. MRC-5 (P 30-35) cells were maintained in Dulbecco's modified Eagle's medium with 10\% FBS. The human endothelial cell lines HUVEC and HMVEC were cultured in HuMedia-MvG medium with growth supplements (Kurabo, Osaka, Japan).
TSU-68 was synthesized by Taiho Pharmaceutical (Tokyo, Japan). Imatinib was provided by Novartis Pharma (Basel, Switzerland). NK4 and anti-HGF antibody were produced as described previously ${ }^{15,16}$ Mouse HGF and neutralizing antibodies for FGF-2 and PDGF were obtained from R\&D Systems (Minneapolis, MN).

\section{ELISA}

Cells $\left(2 \times 10^{5}\right)$ were cultured in $2 \mathrm{~mL}$ modified Eagle's medium (for EHMES-10 and MRC-5) or RPMI 1640 (for MSTO-211H) with $10 \%$ FBS for 48 hours. The culture supernatants were centrifuged and stored at $-80^{\circ} \mathrm{C}$. Tumor cells were lysed in cell lysis buffer containing a phosphatase and proteinase inhibitor cocktail (SigmaAldrich, St. Louis, MO), and their protein concentrations were determined using a BCA protein assay kit (Pierce; Thermo Fisher Scientific, Rockford, IL). The concentrations of VEGF, FGF-2 and PDGF in culture supernatants and cell lysates were determined using enzyme-linked immunosorbent assay (ELISA) kits according to the manufacturer's instructions (R\&D Systems). HGF was quantified by ELISA (IMMUNIS HGF EIA; Institute of Immunology, Tokyo, Japan), according to the manufacturer's instructions. The detection limit for HGF was $0.1 \mathrm{ng} / \mathrm{mL}$. All samples were run in triplicate.

\section{Growth of Tumor Cells and Fibroblasts}

Cell growth was measured by the MTT dye reduction method, as described previously. ${ }^{12}$ Briefly, MRC-5 or MSTO-211H cells $\left(2 \times 10^{3} / 200 \mu \mathrm{L}\right.$ per well), which had been plated in triplicate in 96-well plates, were incubated in culture medium for 24 hours, washed and incubated for 72 hours with TSU-68 or NK4 in fresh culture medium containing $5 \%$ FBS (for MRC-5) or $2.5 \%$ FBS (for MSTO$211 \mathrm{H}$ ) in the presence or absence of FGF-2, PDGF-AA, HGF, or culture supernatants of MPM cells. A 50- $\mu$ L aliquot of stock MTT solution ( $2 \mathrm{mg} / \mathrm{mL}$; Sigma-Aldrich) was added to each well, and the cells were incubated for 2 hours at $37^{\circ} \mathrm{C}$. The medium containing the MTT solution was removed, and the dark blue crystals were dissolved by adding $100 \mu \mathrm{L}$ dimethyl sulfoxide. Absorbance was measured with an MTP-120 microplate reader (Corona Electric, Hitachinaka, Japan) at test and reference wavelengths of 550 and $630 \mathrm{~nm}$, respectively. Percent growth was determined relative to untreated controls. Each experiment was performed at least three times, each with triplicate samples.

\section{Real-Time RT-PCR}

Total cellular RNA was isolated using an RNeasy mini kit and an RNase-free DNase kit (Qiagen, Valencia, CA) according to the manufacturer's protocols. First-strand cDNAs were synthesized using SuperScript III reverse transcriptase (Invitrogen, Carlsbad, CA) with oligo(dT) ${ }_{12-18}$ primers (R\&D Systems). The primer sequences were as follows: human HGF, forward primer 5'-TTCATGATGTCCACGGAAGA-3' and reverse primer 5'-GCCTGGCAAGCTTCATTAAA-3'; human GAPDH, forward primer 5'-GAGTCAACGGATTTGGTCGT-3' and re- 
verse primer 5'-GACAAGCTTCCCGTTCTCAG-3'. Quantitative PCR was performed on an ABI PRISM 7900HT sequence detection system (Applied Biosystems, Foster City, CA) using Power SYBR Green PCR master mix (Applied Biosystems).

\section{Cell Migration Assay}

Cell migration assays were performed using the modified Boyden-chamber method, ${ }^{17}$ with 8- $\mu \mathrm{m}$ pore filters separating the upper and lower Transwell chambers (BD Biosciences, Franklin Lakes, NJ). The cells were serumstarved for 24 hours before the assay. In some experiments, MSTO- $211 \mathrm{H}$ cells $\left(10^{5} / 200 \mu \mathrm{L} 10 \%\right.$ FBS RPMI 1640) were added to the upper chambers, and MRC- 5 cells $\left(10^{4} / 500 \mu \mathrm{L} 10 \%\right.$ FBS RPMI 1640), with or without $300 \mathrm{nmol} / \mathrm{L} \mathrm{NK} 4$, were added to the lower chambers. After 24 hours incubation at $37^{\circ} \mathrm{C}$, the cells that had not migrated were removed from the upper surface of the filters with cotton swabs. The cells that had migrated to the lower surface of the filters were fixed in methanol and stained with H\&E. Migration was quantified by counting cells in six randomly selected fields on each filter under a microscope at $\times 200$ magnification.

\section{Coculture of MPM Cells with Fibroblasts}

Cells were cocultured in Transwell chambers separated by $8-\mu \mathrm{m}$-pore filters. MSTO-211H cells $\left(8 \times 10^{3} / 700 \mu \mathrm{L}\right)$ were placed in each lower chamber, and fibroblasts $\left(10^{4} /\right.$ $300 \mu \mathrm{L}$ ) were placed in each upper chamber, with or without $300 \mathrm{nmol} / \mathrm{L} \mathrm{NK} 4$ in the lower chamber or $3 \mu \mathrm{mol} / \mathrm{L}$ TSU-68 in the upper chamber. After 72 hours, the upper chambers were removed, and cell growth was measured with a Cell Counting Kit-8 (Dojindo Molecular Technologies, Rockville, MD). Each experiment was performed at least three times, each with triplicate samples.

\section{Antibodies and Western Blot Analysis}

Western blotting was performed as described, ${ }^{18}$ using anti-MET, anti-phospho-MET, anti-phospho PDGFR $\alpha$, anti-phospho-FGFR (Cell Signaling Technology, Danvers, $M A$ ), and anti-G3PDH (R\&D Systems) antibodies. Each experiment was performed in triplicate.

\section{Orthotopic Implantation Model}

Cultured MSTO-211H cells were harvested by pipetting, washed twice, and resuspended in PBS, and $1 \times 10^{6}$ cells in $100 \mu \mathrm{L}$ PBS were injected into the thoracic cavity of each SCID mouse. ${ }^{19}$ The mice were treated with TSU-68 (200 $\mathrm{mg} / \mathrm{kg}$, oral gavage), imatinib (25 or $50 \mathrm{mg} / \mathrm{kg}$, i.p.), or NK4 ( 3 or $9 \mathrm{mg} / \mathrm{kg}$, i.p.) daily on days 7 to 20. At 3 weeks after tumor cell inoculation, the mice were sacrificed, their thoracic tumors were carefully removed and weighed, and the volume of pleural effusion was measured.

\section{Immunofluorescence Analysis}

For bromodeoxyuridine (BrdU) staining, the mice were injected with BrdU solution (200 $\mu$ L, i.p.; BrdU staining kit; Zymed Laboratories, South San Francisco, CA). The mice were sacrificed 2 hours later; thoracic tumors were collected and cut into 5-mm fragments and placed in buffered $10 \%$ formalin solution or optimum cutting temperature compound (Bayer, Pittsburgh, PA) and snapfrozen in liquid nitrogen. The frozen tissue sections $(6 \mu \mathrm{m}$ thick) were assayed for the presence of fibroblasts using mouse anti- $\alpha$-SMA antibody (1:500; Sigma-Aldrich) or goat anti-type I collagen antibody (1:200; SouthernBiotech, Birmingham, $\mathrm{AL}$ ) and the proliferating cells were assessed by BrdU staining.

\section{Histology and Immunohistochemistry}

Tumor biopsy specimens from MPM patients, obtained from Hyogo Prefectural Amagasaki Hospital, were fixed on formalin, and embedded in paraffin. The study was approved by the institutional review boards of Hyogo Prefectural Amagasaki Hospital and Kanazawa University.

Sections (5 $\mu \mathrm{m}$ thick) were deparaffinized in xylene and rehydrated in decreasing concentrations of ethanol. The sections were retrieved by microwave treatment for 10 minutes, with immersion in antigen retrieval medium (Immunosaver; Nissin EM, Tokyo, Japan). After blocking endogenous peroxidase activity with $3 \%$ aqueous $\mathrm{H}_{2} \mathrm{O}_{2}$ for 10 minutes, the sections were treated with $5 \%$ normal horse serum and subsequently incubated overnight at $4^{\circ} \mathrm{C}$ with rabbit polyclonal anti-HGF antibody, ${ }^{15}$ goat antiPDGF antibody (R\&D), mouse anti-FGF-2 antibody (BD Biosciences), and rabbit polyclonal anti-MET antibody (IBL Immuno-Biological Laboratories, Gunma, Japan). After a PBS wash, the sections were incubated with biotin-conjugated anti-rabbit $\lg$, anti-goat $\lg$, or antimouse IgG (each 1:200) for 30 minutes at room temperature and subsequently with avidin-biotin-peroxidase complex (ABC) using a Vectastain ABC kit (Vector Laboratories, Burlingame, CA) for 30 minutes. Immunostaining was detected using 3,3'-diaminobenzidine tetrahydrochloride (DAB liquid system; DakoCytomation, Carpinteria, CA). Samples with primary antibodies omitted served as negative controls.

\section{Quantification of Immunohistochemistry and Immunofluorescence}

The five areas containing the highest levels of staining within a section were selected for histological quantification under light or fluorescence microscopy at 40× magnification. The results were evaluated by two investigators (Q.L. and H.U.).

\section{Evaluation of Immunohistochemical Results}

Immunoreactivities of antibodies to FGF-2, PDGF-AA, HGF, MET, and $\alpha$-SMA were scored as follows: -, complete absence of staining or staining of $>5 \%$ of cells; $1+$, staining of $5 \%$ to $50 \%$ of cancer cells; and $2+$, staining of 
$51 \%$ to $100 \%$ of cancer cells or interstitial fibroblasts $(\alpha-S M A)$. Immunoreactivity was evaluated independently by two investigators (H.U. and Y.B.), with discrepancies decided by consensus after joint reevaluation.

\section{Statistical Analysis}

Statistical significance was determined by $t$-test or oneway analysis of variance. All statistical analyses were performed using Prism software (version 4.01; GraphPad Software, San Diego, CA). All tests were two-sided. $P<$ 0.05 was considered significant. Correlations between expression of different cytokines in patient specimens were evaluated by Pearson's correlation analysis. Data are reported as means with 95\% confidence intervals.

\section{Results}

\section{MSTO-211H Cell-Derived FGF-2 and PDGF-AA Promote Growth of Fibroblasts}

Human MPM cells MSTO-211H and EHMES-10 produced different types of thoracic tumors when orthotopically inoculated into the thoracic cavities of SCID mice. EHMES- 10 cells produced a few larger tumors, whereas MSTO-211H cells produced many smaller tumors, most with dispersed white nodes of diameter $<5 \mathrm{~mm} .{ }^{12} \mathrm{~A}$ large number of $\alpha$-SMA-positive fibroblast-like cells infiltrated the tumors produced by MSTO-211H cells, but not EHMES-10 cells (Figure 1A).

To explore the mechanism of fibroblast infiltration, we assessed the production by MPM cell lines of cytokines associated with fibroblast motility. Assays for production of VEGF, a potent motility factor for endothelial cells, showed that MSTO-211H and Y-Meso-14 cells secreted much lower levels of VEGF than did EHMES-10 cells (Figure 1B), as we have previously reported. ${ }^{12}$ In con- trast, lysates of MSTO-211H cells showed large amounts of FGF-2 protein, with the supernatants of these cells containing discernible levels of FGF-2, whereas FGF-2 levels in the lysates of Y-Meso-14 cells were relatively low and those in the supernatants were below the limit of detection. In addition, MSTO-211H and Y-Meso-14 cells secreted high concentrations of PDGF-AA (Figure 1B), but not PDGF-AB or PDGF-BB (data not shown).

When we assessed the effects of these cytokines on fibroblasts by using the human fibroblast cell line MRC-5, we found that FGF-2 $(P<0.001)$ and/or PDGF-AA $(P<$ $0.01)$ significantly stimulated the growth of MRC- 5 cells (Figure 1C). TSU-68, which targets the tyrosine kinases of FGFR1, PDGFR, and VEGFR, did not inhibit the baseline growth of MRC-5 cells, but it abrogated the effects of FGF-2 and PDGF-AA. In contrast, TSU-68, as well as exogenously added FGF-2 and PDGF-AA, had no effect on the growth of MSTO-211H cells, indicating that FGF-2 and PDGF-AA are not autocrine growth factors for MSTO$211 \mathrm{H}$ cells. The supernatant of MSTO- $211 \mathrm{H}$ cells stimulated the growth of MRC- 5 cells $(P<0.001)$, an effect completely abrogated by TSU-68. In addition, FGF-2 and PDGF-AA increased the migration of MRC-5 cells (see Supplemental Figure S1 at $h$ ttp://ajp.amjpathol.org). Western blot analysis showed that the supernatants of MSTO$211 \mathrm{H}$ cells activated FGFR1 and PDGFR $\alpha$ in MRC-5 cells, and that the phosphorylation of these receptors was inhibited by TSU-68 (Figure 1D). Taken together, these results suggest that FGF-2 and PDGF-AA produced by MSTO$211 \mathrm{H}$ cells promoted the growth and migration of fibroblasts via the activation of FGFR1 and PDGFR $\alpha$.

\section{FGF-2 and PDGF-AA Enhance HGF Production by Fibroblasts}

We next assessed the role of infiltrating fibroblasts in MPM. We hypothesized that one or more cytokines pro-
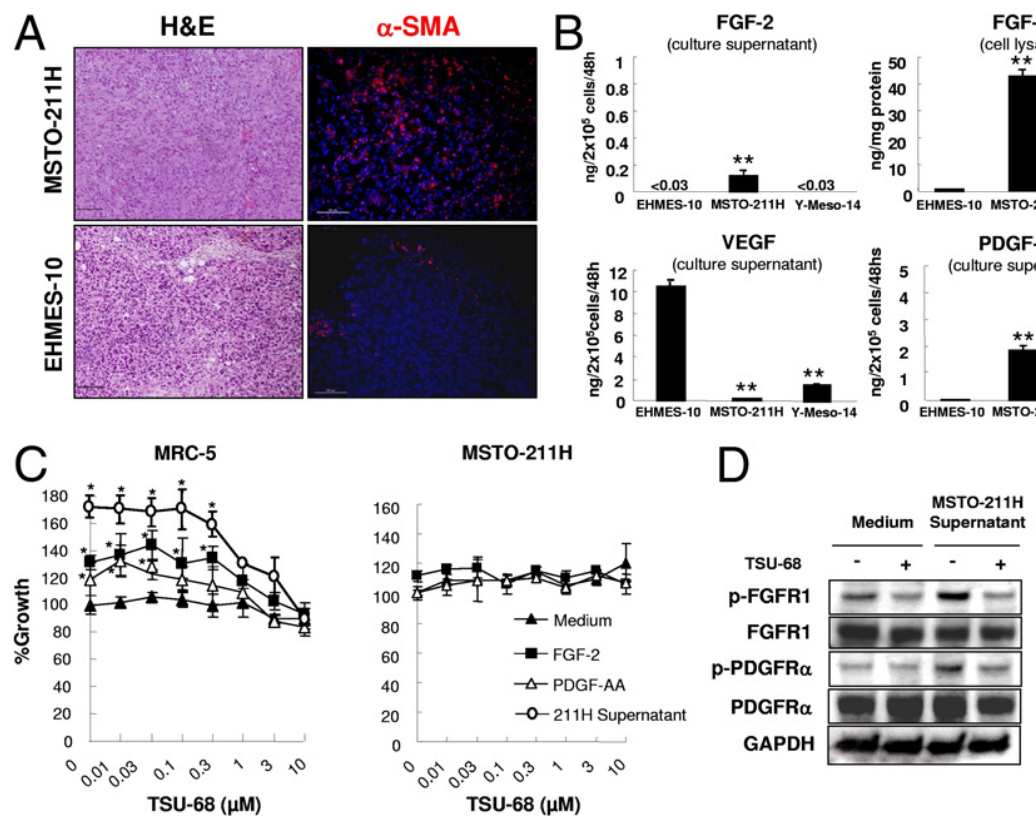

Figure 1. MSTO-211H cell-derived FGF-2 and PDGF-AA promote growth of fibroblasts. A: Thoracic tumors produced by MPM cells in SCID mice were stained with H\&E and by immunofluorescence for $\alpha$-SMA (red) and DAPI (blue) Scale bars $=100 \mu \mathrm{m}$. B: ELISA assays of FGF-2, VEGF, and PDGF-AA in the culture supernatan of MPM cells and of FGF-2 in cell lysates. ${ }^{*} P<$ $0.05{ }^{* *} P<0.01$ versus EHMES-10. C: MRC- 5 or MSTO-211H cells were cultured in the presence of FGF-2 $(20 \mathrm{ng} / \mathrm{mL})$, PDGF-AA $(20 \mathrm{ng} / \mathrm{mL})$, or the culture supernatant of MSTO- $211 \mathrm{H}$ cells $(2 \times$ $10^{5} / 2 \mathrm{~mL} / 48$ hours), with or without TSU-68 After 72 hours, the growth of MRC- 5 or MSTO$211 \mathrm{H}$ cells was determined by MTT assay. ${ }^{*} P<$ 0.01 versus medium alone. D: TSU-68 abrogates the phosphorylation of FGFR1 and PDGFR $\alpha$ in duced by the supernatant of MSTO-211H cells. MRC-5 cells were incubated with or withou TSU-68 $(10 \mu \mathrm{mol} / \mathrm{L})$ in the presence or absence of the supernatant of MSTO-211H cells for 15 minutes. The cells were lysed and proteins were detected by immunoblotting. 
duced predominantly by fibroblasts might influence MPM behavior. We therefore compared the cytokine production profiles of MRC-5 and MSTO-211H cells using a cytokine antibody array (see Supplemental Figure S2 at http://ajp.amjpathol.org). Whereas both MSTO-211H and MRC- 5 cells produced IL-6, IL-8, and the growth-regulated oncogenes IGFBP- 1 and MCP-1, only MRC- 5 cells produced high levels of hepatocyte growth factor/scatter factor (HGF). We therefore assayed the production of HGF by various cell lines. Although neither the MPM cell lines (MSTO-211H, Y-Meso-14, and EHMES-10) nor the endothelial cell lines (HUVEC and HMVEC) secreted discernible levels of HGF (Figure 2A), MRC-5 and IMR-90 cells and primary cultured patient fibroblasts (PF) produced high levels of HGF, as reported previously. ${ }^{7,20}$ We also evaluated the effects of FGF-2 and PDGF-AA on fibroblast production of HGF. Both FGF-2 $(P<0.05)$ and PDGF-AA $(P<0.01)$ significantly stimulated HGF production of MRC-5, at both the protein (Figure 2B) and mRNA (Figure 2C) levels. Similarly, treatment of another human lung fibroblast cell line, IMR-90, with FGF-2 and PDGF-AA stimulated HGF production (see Supplemental Figure S3 at http://ajp.amjpathol.org). These results clearly indicate that FGF-2 and PDGF-AA secreted by MSTO- $211 \mathrm{H}$ cells stimulated fibroblast growth and production of HGF.

\section{HGF Derived from Fibroblasts Enhances the Growth and Motility of MPM Cells}

To clarify the role of HGF, which can be produced by fibroblasts, on the biological behavior of MPM cells, we assessed the effect of HGF on the growth of MSTO-211H cells. In contrast to FGF-2 or PDGF-AA, HGF enhanced the growth of MSTO-211H cells, an effect inhibited by anti-HGF antibody (Figure 2D). More importantly, the HGF antagonist NK4 abrogated the HGF-stimulated growth of MSTO- $211 \mathrm{H}$ cells, as well as slightly inhibiting the constitutive growth of MSTO-211H cells (Figure 2D). Furthermore, the supernatant of MRC-5 cells, as well as HGF, stimulated the phosphorylation of MET, the specific receptor of HGF, in MSTO-211H cells, an effect inhibited by NK4 (Figure 2E). We therefore evaluated the effect of fibroblasts on the motility of MSTO-211H cells. HGF dramatically enhanced the motility of MSTO-211H cells, an effect blocked by NK4 (Figure 2F). In addition, HGF significantly stimulated the growth and motility of Y-Meso-14 cells, and these effects were blocked by NK4. In contrast, HGF stimulated neither growth nor motility of EHMES-10 cells (see Supplemental Figure S4 at http://ajp.amjpathol. org). These results indicate that fibroblast-derived HGF promotes the growth and motility of MSTO-211H and Y-Meso14 cells.

\section{Simultaneous Blockade of FGFR1 and PDGFRs Inhibits Growth of MPM Cells in a Coculture System}

Our findings suggested the presence of a malignant cytokine network (malignant crosstalk) involving MPM cells
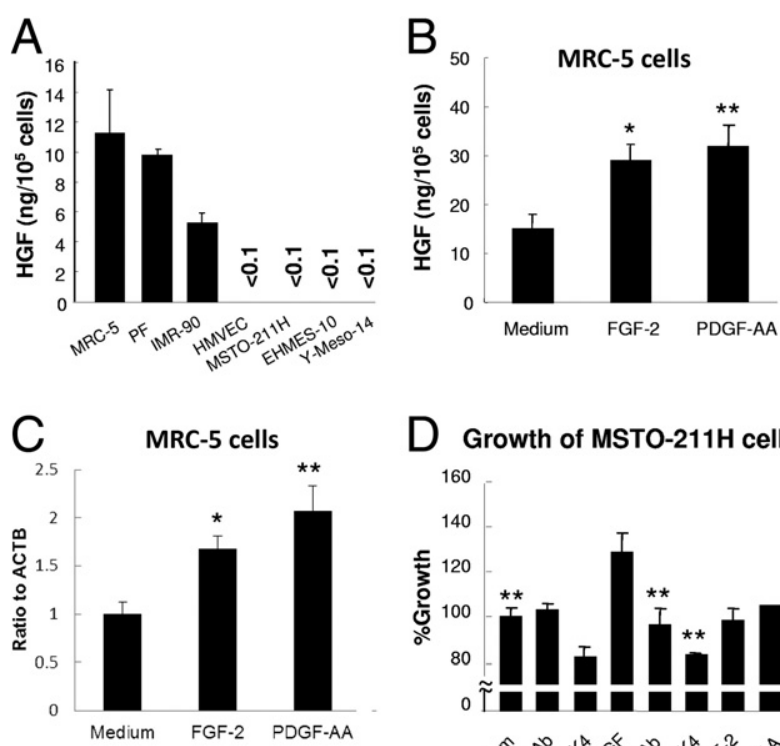

D Growth of MSTO-211H cells

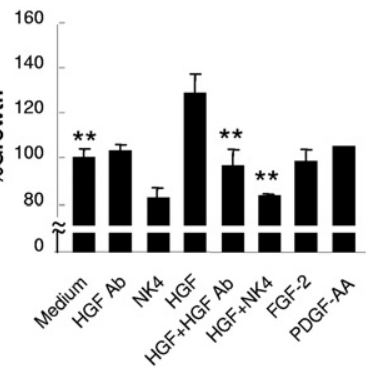

$E$

$\mathrm{F}$

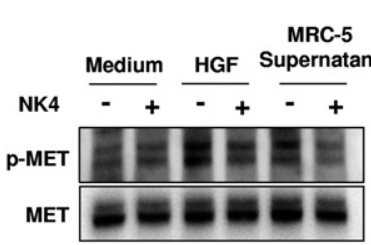

Migration of MSTO-211H cells

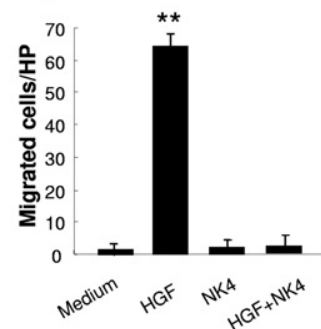

Figure 2. HGF derived from fibroblasts enhances the growth and motility of MPM cells. A: HGF production by MPM (EHMES-10, MSTO-211H), fibroblast (MRC-5 and IMR-90), Primary cultured patient fibroblast (PF), and endothelial (HMVEC) cell lines. Cells $\left(2 \times 10^{5} / 2 \mathrm{~mL}\right)$ were incubated in medium for 8 hours, the culture supernatants were harvested, and HGF concentrations were determined by ELISA. B: FGF-2 and PDGF-AA enhance HGF production by fibroblasts. MRC- 5 cells $\left(2 \times 10^{5} / 2 \mathrm{~mL}\right)$ were cultured for 48 hours in the presence of FGF-2 $(20 \mathrm{ng} / \mathrm{mL})$ or PDGF-AA $(20 \mathrm{ng} / \mathrm{mL})$, and HGF concentrations in culture supernatants were determined by ELISA. ${ }^{*} P<0.05$; ${ }^{* *} P<0.01$ versus medium alone. C: FGF-2 and PDGF-AA increase HGF mRNA expression in fibroblasts. HGF mRNA expression by MRC-5 cells pretreated with FGF-2 $(20 \mathrm{ng} / \mathrm{mL})$ or PDGF-AA $(20 \mathrm{ng} / \mathrm{mL})$ for 48 hours was determined by real-time RT-PCR. ${ }^{*} P<0.05 ;{ }^{* *} P<0.01$ versus medium alone. D: HGF increases MPM cell growth. MSTO-211H cells were cultured with 20 $\mathrm{ng} / \mathrm{mL}$ of HGF, FGF-2, or PDGF-AA in the presence or absence of NK4 (300 $\mathrm{nmol} / \mathrm{L}$ ) for 72 hours, and cell growth was determined by MTT assay. ${ }^{*} P<$ $0.05,{ }^{* *} P<0.01$ versus HGF. E: NK4 abrogates MET phosphorylation induced by fibroblast-derived HGF in MPM cells. MSTO- $211 \mathrm{H}$ cells were treated with or without NK4 $(300 \mathrm{nmol} / \mathrm{L})$ in the presence or absence of HGF $(20 \mathrm{ng} / \mathrm{mL})$ or the supernatant of MRC- 5 cells $\left(10^{6} / \mathrm{mL} / 48\right.$ hours) for 30 minutes. The cells were lysed and proteins were detected by immunoblotting. The lower band (p145 MET) corresponds to the mature form of MET; the upper band (p170 MET) corresponds to the immature MET precursor. F: HGF induces the migration of MSTO-211H cells. The assay was performed in triplicate as described under Materials and Methods. ${ }^{*} P<0.05,{ }^{* * *} P<0.01$ versus medium alone

and fibroblasts (Figure 3A). We therefore used a coculture system to determine whether such a malignant network exists between MPM and fibroblast cells. Cocultured MRC- 5 cells stimulated the growth of MSTO-211H cells, an effect blocked by both TSU-68 and the combination of anti-FGF-2 and anti-PDGF neutralizing antibodies (Figure 3B). This growth was also abrogated by either 

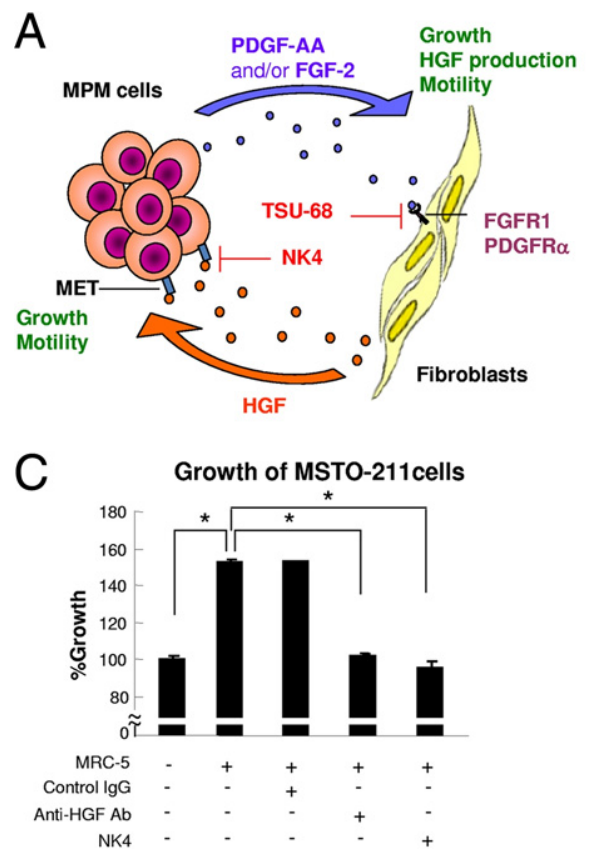

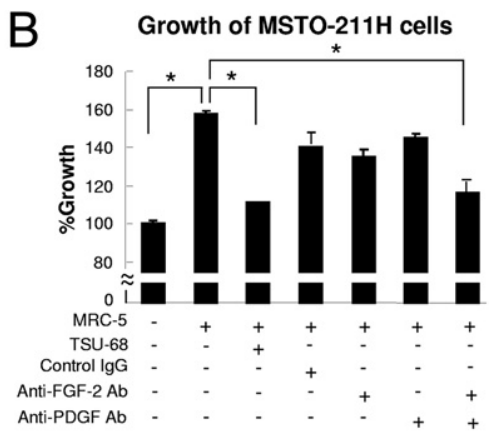

D

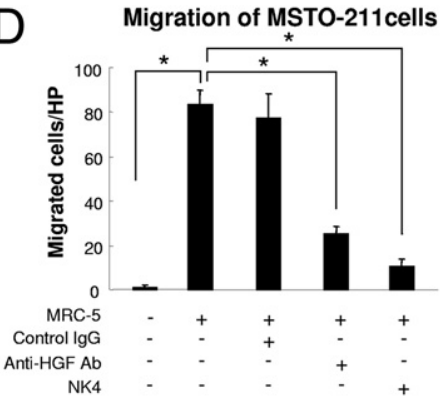

Figure 3. Simultaneous blockade of FGFR1 anc PDGFRs inhibits the growth of MPM cells in a coculture system. A: Schema of the malignant cytokine network between MPM cells and stromal tumor-associated fibroblasts (TAFs). B: TSU-68 circumvents the growth of MPM cells induced by fibroblasts in the coculture system. MSTO- $211 \mathrm{H}$ cells were cocultured with MRC-5 cells with or without TSU-68 (10 $\mu \mathrm{mol} / \mathrm{L}$ ), control IgG, anti-FGF-2 antibody, and/or anti-PDGF antibody $(1 \mu \mathrm{g} / \mathrm{mL})$ for 72 hours. MPM cell growth was determined using a Cell Counting Kit-8. C: Inhibition of HGF blocks the growth of MPM cells induced by fibroblasts in a coculture system. MSTO- $211 \mathrm{H}$ cells were cocultured with MRC-5 cells with control IgG, anti-HGF neutralizing antibody $(1 \mu \mathrm{g} / \mathrm{mL})$, or NK4 $(300 \mathrm{nmol} / \mathrm{L})$ for 72 hours, and MPM cell growth was determined. D: Blockade of HGF prevents MSTO-211H cell migration induced by MRC-5 cells. The assay was performed in triplicate as described under Materials and Methods. ${ }^{*} P<0.01$.
anti-HGF antibody or NK4 (Figure 3C). Moreover, cocultured MRC-5 cells markedly induced the migration of MSTO-211H cells, an effect also inhibited by either antiHGF antibody or NK4 (Figure 3D). Consistent with these observations, coculture with MRC-5 cells stimulated the growth of $Y$-Meso-14 cells, and this effect was blocked by TSU-68, NK4, or anti-HGF antibody. Either anti-HGF antibody or NK4 inhibited the migration of Y-Meso-14 cells induced by coculture with MRC-5 cells (see Supplemental Figure S5 at http://ajp.amjpathol.org). These findings clearly point to the existence of a malignant cytokine network between MPM cells and fibroblasts in vitro.

\section{Malignant Cytokine Network between MPM Cells and Patient Fibroblasts or Mouse Fibroblasts}

To assess whether this malignant cytokine network is unique to MPM cells and MRC-5 human fibroblast cell lines, we cocultured MSTO-211 $\mathrm{H}$ cells with either primary cultured patient fibroblasts or the mouse fibroblast cell line 3T3-Swiss. Similar to the effect on MRC-5 cells, the patient fibroblasts induced the migration of both MSTO$211 \mathrm{H}$ and Y-Meso-14 cells, and anti-HGF antibody or NK4 inhibited the migration induced by the patient fibroblasts (Figure 4A). Cocultured patient fibroblasts also stimulated growth of MSTO-211H and Y-Meso-14 cells. These effects were inhibited by TSU-68, NK4, or anti-HGF antibody (Figure 4, B and C). These results indicate that the cytokine network is not specific to the MRC-5 fibroblast cell line.

Moreover, similar to its effect on human fibroblasts, TSU-68 did not inhibit the growth of 3T3-Swiss cells. PDGF-AA, but not FGF-2, significantly up-regulated the growth of 3T3-Swiss cells $(P<0.05)$, an effect blocked by TSU-68 (Figure 4D). Both exogenous mouse HGF and the supernatant of 3T3-Swiss cells induced MET phosphorylation of MSTO-211H cells, effects abrogated by NK4 (Figure 4E), indicating that mouse HGF can activate human MPM cells. These results were consistent with previous findings showing that the activity of HGF is not always species-specific. ${ }^{21}$ Although mouse HGF did not promote the growth of MPM cells (data not shown), 3T3Swiss cells induced their migration, an effect inhibited by NK4 (Figure 4F). These findings suggest that MPM cells also stimulate mouse fibroblasts to promote the progression of MPM cells.

\section{Presence of Malignant Cytokine Network between MPM and Microenvironment in Vivo}

We next examined whether the malignant cytokine network could promote the progression of MPM cells in vivo. To assess this possibility, MSTO-211H or Y-Meso-14 cells were inoculated orthotopically into the thoracic cavities of SCID mice and the mice were treated with TSU-68 (an inhibitor of FGFR1 and PDGFRs), imatinib (an inhibitor of PDGFRs), or NK4 (an inhibitor of HGF/MET). MSTO-211H cells produced thoracic tumors and a small volume of pleural effusion, whereas Y-Meso-14 cells produced thoracic tumors and large volumes of pleural effusion. We previously reported that treatment of these mice with the anti-VEGF antibody bevacizumab did not significantly inhibit the progression of MSTO-211H cells, suggesting that VEGF is not primarily responsible for progression in an MSTO-211H mouse model. ${ }^{12}$ Although tumor concentrations of VEGF, PDGF-AA, and FGF-2 were not altered by either TSU-68 or imatinib (data not shown), both treatments significantly inhibited the growth of thoracic tumors (Table 1, experiments 1, 2, and 4; Figure 5A). Furthermore, either TSU-68 or imatinib significantly inhibited the production of pleural effusion by Y-Meso-14 cells (Table 1, 

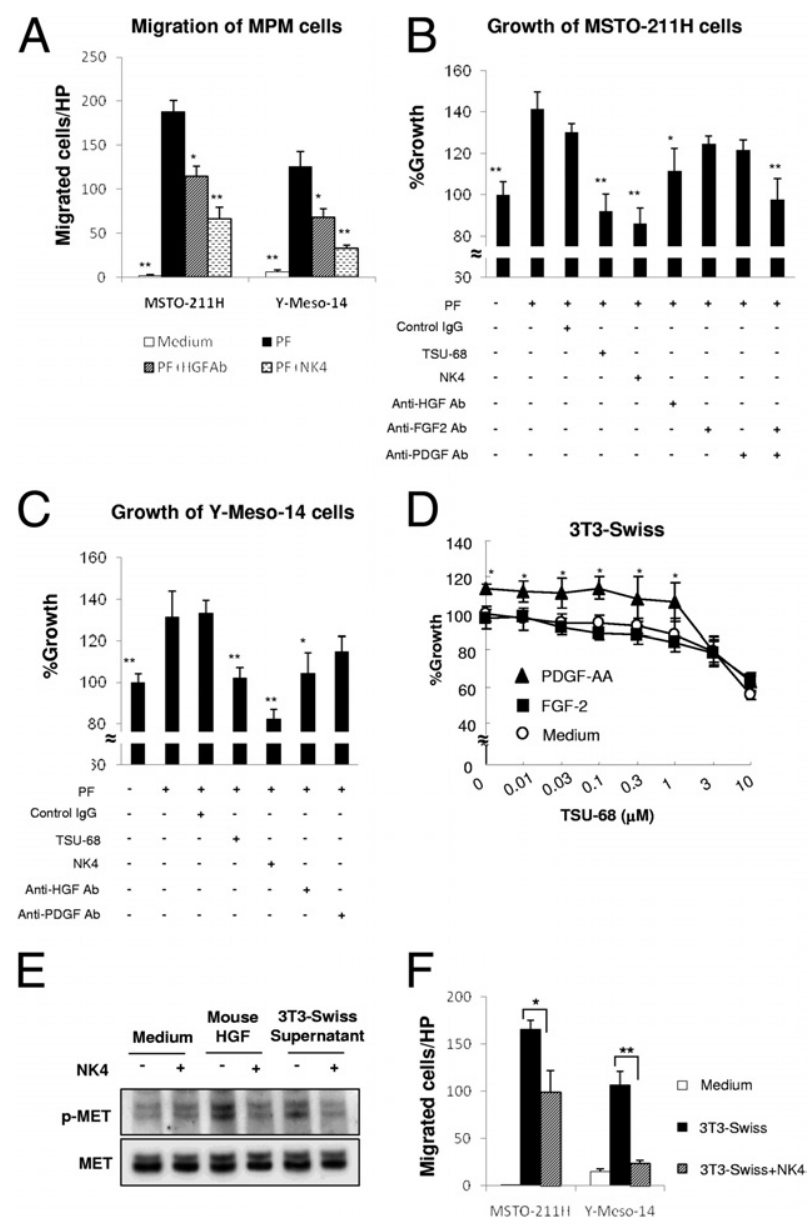

Figure 4. Malignant cytokine network between MPM cells and patient fibroblasts or mouse fibroblasts. A: Blockade of HGF prevents MSTO-211H or Y-Meso-14 cell migration induced by primary cultured patient fibroblasts (PF). The assay was performed in triplicate as described under Materials and Methods. ${ }^{*} P<0.05,{ }^{* *} P<0.01$ versus PF. B and C: TSU-68, NK4, and anti-HGF antibody blocked the growth of MSTO-211H cells induced by PF in the coculture system. MSTO-211H (B) or Y-Meso-14 (C) cells were cocultured with PF cells with or without TSU-68 (10 $\mu \mathrm{mol} / \mathrm{L})$, control IgG, NK4 $(300 \mathrm{nmol} / \mathrm{L})$, anti-HGF antibody $(1 \mu \mathrm{g} / \mathrm{mL})$, anti-FGF-2 antibody, and/or anti-PDGF antibody $(1 \mu \mathrm{g} / \mathrm{mL})$ for 72 hours. MPM cell growth was determined using a Cell Counting Kit-8. ${ }^{*} P<0.05$, ${ }^{* * *} P<0.01$ versus PF. D: PDGF-AA $(20 \mathrm{ng} / \mathrm{mL})$, but not FGF-2 $(20 \mathrm{ng} / \mathrm{mL})$, enhances the growth of the mouse fibroblast 3T3-Swiss cell line, as determined by MTT assays. ${ }^{*} P<0.05$. E: NK4 abrogates MET phosphorylation induced by mouse fibroblast-derived HGF in MPM cells. MSTO-211H cells were treated with or without NK4 (300 $\mathrm{nmol} / \mathrm{L})$ in the presence or absence of mouse HGF $(100 \mathrm{ng} / \mathrm{mL})$ or the supernatant of $3 \mathrm{~T} 3$-Swiss cells $\left(10^{6} / \mathrm{mL} / 48\right.$ hours $)$ for 30 minutes. The cells were lysed and proteins were detected by immunoblotting. F: NK4 decreases the migration of MPM cells induced by mouse fibroblasts. Migration of MSTO-211H cells and Y-Meso-14 cells in the presence or absence of NK4 $(300 \mathrm{nmol} / \mathrm{L})$ cocultured with 3T3-Swiss cells was assayed as described under Materials and Methods. ${ }^{*} P<0.05,{ }^{* *} P<0.01$.

experiment 4). Histological analyses using BrdU staining to identify proliferating cells and antibodies to type I collagen or $\alpha$-SMA showed that treatment with TSU-68 reduced the number of tumor-associated proliferating fibroblasts in tumors produced by both MSTO-211 $\mathrm{H}$ and Y-Meso-14 cells (Figure 5B). These results suggest that inhibition of FGFR1 and PDGFRs suppressed the recruitment and/or growth of tumor-associated fibroblasts and thereby inhibited the growth of MPM tumors.

We also found that treatment with $9 \mathrm{mg} / \mathrm{kg} \mathrm{NK} 4$ significantly inhibited the growth of thoracic tumors (Table 1 , experiments 3 and 4; Figure 5A). NK4 also inhibited the production of pleural effusion by Y-Meso-14 cells. In NK4treated tumors, the number of tumor-associated fibroblasts tended to be decreased, but the difference was not statistically significant. However, the numbers of proliferating cells, including MPM cells and fibroblasts, were markedly decreased (Figure 5B), indicating that, even though inhibition of HGF-MET signaling did not affect the recruitment and/or growth of tumor-associated fibroblasts, it suppressed the growth of MPM tumors. These results strongly suggest that MPM cells stimulate fibroblasts to promote progression in vivo via a malignant cytokine network consisting of FGF-2, PDGF-AA, and HGF.

\section{High Immunoreactivity for FGF-2, PDGF-AA, and HGF in Tumors from MPM Patients}

To assess the clinical relevance of immunoreactivity for FGF-2, PDGF-AA, and HGF, we examined whether these cytokines could be detected in clinical specimens obtained from MPM patients. We analyzed 51 tumors from 51 MPM patients (Table 2; see also Supplemental Figure S6 at $h$ ttp://ajp.amjpathol.org). We found that 46 (90\%), 40 (78\%), and 50 (98\%) tumors showed positive staining for FGF-2, PDGF-AA, and HGF, respectively. Moreover, all $51(100 \%)$ tumors were positive for MET, including 47 $(92 \%)$ showing high positivity $(2+)$, indicating the importance of expression of the MET ligand (HGF) for controlling HGF-induced biological activity in MPM. Notably, of the 34 tumors highly positive (2+) for HGF, 20 (59\%) were also highly positive (2+) for FGF-2 and/or PDGFAA. Furthermore, tumors from three patients $(3 / 51$, or $9 \%)$ were highly positive $(2+)$ for all three. Statistical correlation analysis showed that FGF-2 and PDGF-AA expression were correlated $(P<0.05)$, suggesting that these two cytokines are frequently expressed coordinately in MPMs, as in MSTO- $211 \mathrm{H}$ cells.

Of the 51 tumors, 27 (53\%) were highly positive $(2+)$ for $\alpha$-SMA. Of these 27 tumors, $17(63 \%), 5(19 \%)$, and 17 (63\%) were highly positive (2+) for FGF-2, PDGF-AA, and HGF, respectively. Moreover, 10 of the 17 (59\%) HGF-positive tumors were also positive for FGF-2 and/or PDGF-AA.

Taken together, these results strongly suggest that a local cytokine network between mesothelioma cells and fibroblasts is involved in the progression of a considerable proportion of MPM tumors.

\section{Discussion}

The tumor microenvironment has been the subject of intensive investigation and has been shown to facilitate tumor growth and distant metastasis. For example, in breast and colon cancer models, the primary tumors have been reported to activate bone marrow in their systemic environment and to instigate the growth of indolent distant tumors, a process called systemic instigation. ${ }^{6}$ In contrast, MPM is a locally aggressive disease with intrathoracic dissemination, and rarely causes distant metastases except at end stages. We have shown here that local instigation in MPM is mediated by malig- 
Table 1. Therapeutic Efficacy of TSU-68, Imatinib, and NK4 on Production of Thoracic Tumor and Pleural Effusion Produced by MSTO$211 \mathrm{H}$ and Y-MESO-14 Cells in SCID Mice

\begin{tabular}{|c|c|c|c|c|c|c|c|}
\hline \multirow[b]{3}{*}{ Treatment $^{\dagger \ddagger}$} & \multirow[b]{3}{*}{ Dose (mg/kg) } & \multicolumn{3}{|c|}{ Thoracic tumor } & \multicolumn{3}{|c|}{ Pleural effusion } \\
\hline & & \multirow[b]{2}{*}{ Incidence } & \multicolumn{2}{|c|}{ Weight (mg) } & \multirow[b]{2}{*}{ Incidence } & \multicolumn{2}{|c|}{ Volume $(\mu \mathrm{L})$} \\
\hline & & & Median & Range & & Median & Range \\
\hline \multicolumn{8}{|c|}{ MSTO-211H } \\
\hline \multicolumn{8}{|l|}{ Experiment 1} \\
\hline Control (CMC) & & $10 / 10$ & 378 & $132-773$ & $5 / 10$ & 40 & $0-400$ \\
\hline TSU-68 ${ }^{+}$ & 200 & $10 / 10$ & $164^{\star \star}$ & 29-254 & $2 / 10$ & $<10$ & $0-180$ \\
\hline \multicolumn{8}{|l|}{ Experiment 2} \\
\hline Control (saline) & & $5 / 5$ & 187 & $94-327$ & $3 / 5$ & 30 & $0-140$ \\
\hline Imatinib & 25 & $4 / 5$ & $83^{*}$ & $0-155$ & $2 / 5$ & $<10$ & $0-180$ \\
\hline Imatinib & 50 & $4 / 5$ & $76^{*}$ & $0-143$ & $1 / 5$ & $<10$ & $0-30$ \\
\hline \multicolumn{8}{|l|}{ Experiment 3} \\
\hline Control (saline) & & $5 / 5$ & 356 & $164-437$ & $2 / 5$ & $<10$ & $0-200$ \\
\hline NK4 & 3 & $4 / 5$ & 336 & $0-448$ & $3 / 5$ & 40 & $0-320$ \\
\hline NK4 & 9 & $3 / 5$ & $40 *$ & $0-276$ & $1 / 5$ & $<10$ & $0-300$ \\
\hline \multicolumn{8}{|c|}{ Y-Meso-14 } \\
\hline Experiment 4 & & & & & & & \\
\hline Control (saline) & & $5 / 5$ & 320 & $270-370$ & $5 / 5$ & 700 & $500-800$ \\
\hline TSU-68 & 200 & $5 / 5$ & $140^{\star \star}$ & $130-160$ & $5 / 5$ & $200^{*}$ & $50-400$ \\
\hline Imatinib & 25 & $5 / 5$ & $60^{* *}$ & $10-150$ & $3 / 5$ & $50^{*}$ & $0-350$ \\
\hline $\mathrm{NK} 4^{\ddagger}$ & 9 & $5 / 5$ & $140^{\star \star}$ & $0-230$ & $3 / 5$ & $200^{*}$ & $0-400$ \\
\hline
\end{tabular}

${ }^{\star} P<0.05 ;{ }^{* \star} P<0.01$, versus control group (two-tailed nonparametric $t$-test).

${ }^{+}$MSTO- $211 \mathrm{H}$ cells $\left(1 \times 10^{6}\right)$ or Y-Meso- 14 cells $\left(1 \times 10^{6}\right)$ were inoculated into thoracic cavity of SCID mice on day 0 . Mice were treated daily on days 7 to 20 (MSTO-211H) or days 7 to 27 (Y-Meso-14). All mice were sacrificed on day 21 (MSTO-211H) or day 28 (Y-Meso-14).

FRoute of administration: oral gavage for TSU-68 and intraperitoneal for imatinib and NK4.

$\mathrm{CMC}$, carboxymethylcellulose-based vehicle solution.

nant cytokine network involving MPM and TAFs. MPM cells produce FGF-2 and PDGF-AA, which stimulate the growth and/or motility of fibroblasts and up-regulate their production of HGF. Fibroblast-derived HGF, in turn, stimulates the growth and/or motility of MPM cells. Importantly, the infiltration of TAFs and the simultaneous expression of three cytokines (FGF-2, PDGF-AA, and HGF) were detected in clinical specimens obtained from patients with MPM. These results indicate that MPMs recruit and activate TAFs by secreting FGF-2 and PDGF-AA, and that activated TAFs produce HGF, which promotes the dissemination of MPM in the thoracic cavity. These three cytokines may therefore be therapeutic targets in the treatment of MPM.
A

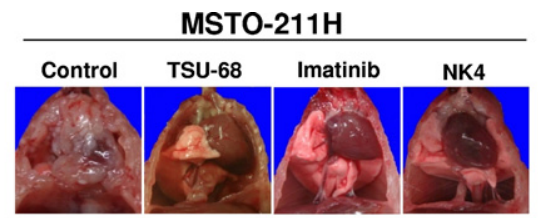

B
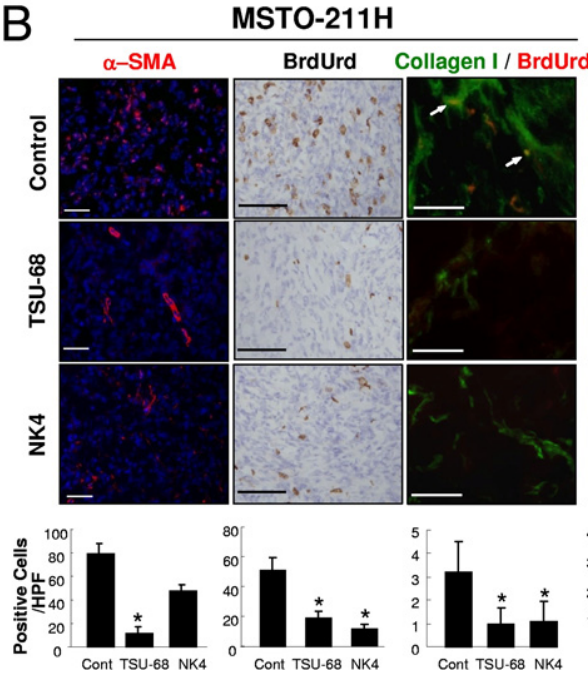
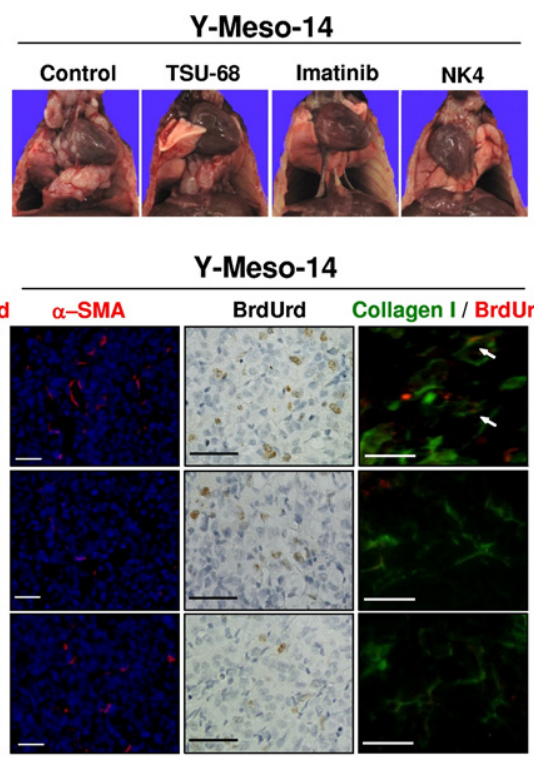

Y-Meso-14

BrdUrd Collagen I/ BrdUrd

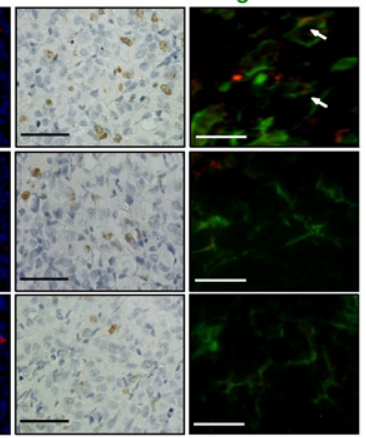

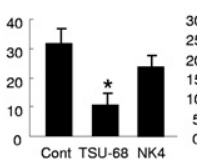

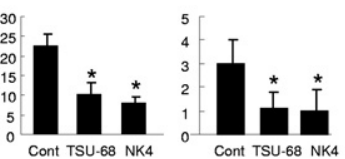

Figure 5. TSU-68, imatinib, and NK4 inhibit the production of thoracic tumors by MPM cells in an orthotopically implanted SCID mouse model. A: Macroscopic appearance of thoracic tumors caused by MSTO-211H or Y-Meso-14 cells treated with TSU-68, imatinib, or NK4. The thoracic tumors were evaluated as described under Materials and Methods. B: Histological analysis of the same tumors. The thoracic tumors were analyzed by immunohistochemistry (type I collagen and BrdU) and immunofluorescence $(\alpha-$ SMA and double staining of BrdU and type I collagen). In double staining, red fluorescence indicates BrdU and green fluorescence indicates type I collagen; arrows mark double-positive cells (proliferating fibroblasts). Scale bars $=50$ $\mu \mathrm{m}$. The corresponding graphs show the mean number of positive cells per high-power field (HPF), from five independent areas. ${ }^{*} P<0.01$ versus control. Negative controls without primary antibodies did not show discernible stain ing for $\alpha$-SMA, BrdU, or type I collagen (data not shown). 
Table 2. Demographic Characteristics and Tumor Immunoreactivity for FGF-2, PDGF-AA, HGF, and MET in Malignant Pleural Mesothelioma Patients

\begin{tabular}{|c|c|}
\hline Characteristic & MPM patients \\
\hline Sample size & $N=51$ \\
\hline \multicolumn{2}{|l|}{ Sex, no. (\%) } \\
\hline $\mathrm{M}$ & $42(82)$ \\
\hline $\mathrm{F}$ & $9(18)$ \\
\hline \multicolumn{2}{|l|}{ Age (years) } \\
\hline Median & 67 \\
\hline Range & $38-80$ \\
\hline \multicolumn{2}{|c|}{ Exposure to asbestos, no. (\%) } \\
\hline Yes & $18(35)$ \\
\hline No & $13(25)$ \\
\hline Unknown & $20(39)$ \\
\hline \multicolumn{2}{|l|}{ Histology, no. (\%) } \\
\hline Epithelial & $26(51)$ \\
\hline Biphasic & $15(29)$ \\
\hline Sarcomatoid & $10(20)$ \\
\hline \multirow{2}{*}{\multicolumn{2}{|c|}{ Expression in tumors, ${ }^{*}$ no. (\%) }} \\
\hline FGF-2 & \\
\hline- & $5(10)$ \\
\hline $1+$ & $16(31)$ \\
\hline $2+$ & $30(59)$ \\
\hline \multicolumn{2}{|l|}{ PDGF-AA } \\
\hline- & $11(22)$ \\
\hline $1+$ & $33(65)$ \\
\hline $2+$ & $7(14)$ \\
\hline \multicolumn{2}{|l|}{ HGF } \\
\hline- & $1(2)$ \\
\hline $1+$ & $16(31)$ \\
\hline $2+$ & $34(67)$ \\
\hline \multicolumn{2}{|l|}{ MET } \\
\hline- & $0(0)$ \\
\hline $1+$ & $4(8)$ \\
\hline \multirow{2}{*}{\multicolumn{2}{|c|}{$\alpha-S M A$}} \\
\hline & \\
\hline- & $10(20)$ \\
\hline $1+$ & $14(27)$ \\
\hline $2+$ & $27(53)$ \\
\hline
\end{tabular}

${ }^{*}-$, complete absence of staining or staining of $<5 \%$ of cells; $1+$, staining of $5 \%$ to $50 \%$ of cancer cells (or interstitial fibroblasts, $\alpha$-SMA); $2+$, staining of $51 \%$ to $100 \%$ of cancer cells (or interstitial fibroblasts, $\alpha$-SMA).

$\mathrm{F}$, female, M, male.

All three cytokines (FGF-2, PDGF-AA, and HGF) are ligands of receptor tyrosine kinases (FGFR1, PDGFR $\alpha$, and $M E T$, respectively). Several studies have suggested that FGF-2 and PDGF-AA are involved in the pathogenesis of MPM. ${ }^{22,23}$ Moreover, significant concentrations of HGF have been detected in pleural effusions obtained from patients with MPM. ${ }^{24}$ Although FGF-2 and PDGFs have been reported to be growth factors for several MPM cell lines, neither FGF-2 nor PDGF-AA stimulated the growth of MPM cells, whereas HGF stimulated not only the migration but the growth of MSTO-211H and Y-Meso-14 cells, consistent with prior observations. ${ }^{25}$ Meanwhile, although anti-FGF-2 antibody alone or antiPDGF antibody alone only slightly inhibited the MPM proliferation up-regulated by MRC-5, combined use of both antibodies almost reversed the effect of MRC-5 (Figure 3B). These observations indicate that FGF-2 or PDGF-AA alone may be sufficiently functional to maintain the cytokine network, further suggesting functional redundancy between FGF-2 and PDGF in MRC-5 cells. Although the role of each cytokine has been evaluated individually, to our knowledge this is the first comprehensive analysis to show their association and the interaction between MPM and TAFs, using orthotopically implanted SCID mice and clinical specimens.

Notably, mouse HGF induced MET phosphorylation and stimulated the motility, but not the growth, of human MPM cells, whereas human HGF stimulated both motility and growth. Regarding the effect of mouse HGF on human cells, results of previous reports are controversial. Burgess et $\mathrm{al}^{26}$ showed that mouse HGF does not potently activate human MET signaling; however, Previdi et $\mathrm{al}^{27}$ recently demonstrated that mouse HGF activated MET in human breast cancer cells. Taken together with our results, these findings suggest that i) MET signaling induced by mouse HGF is not as strong as that induced by human HGF, ii) MET signaling induced by mouse HGF is sufficient to stimulate the motility of human MPM cells, and iii) stronger MET signaling is required to stimulate the growth of human MPM cells. Although mouse HGF stimulated only motility, suppression of invasive growth by blockade of HGF/MET signaling had therapeutic value, ${ }^{28}$ because MPM is an aggressive neoplasm characterized by extensive invasive growth.

Although human FGF-2 stimulated the growth of human fibroblasts, it did not stimulate the growth of mouse fibroblasts. Under the same experimental conditions, human PDGF-AA stimulated the growth of both human and mouse fibroblasts. Moreover, imatinib, which inhibits PDGFR signaling, markedly inhibited the progression of MSTO-211H and Y-Meso-14 cells in an orthotopic implantation model that mimics the MPM microenvironment in humans. Clinical trials of imatinib monotherapy in MPM have shown limited efficacy, ${ }^{29,30}$ suggesting that, although the PDGF/PDGFRs axis is the signaling pathway responsible for fibroblast motility and growth in mice, the pathway in humans also involves the FGF-2/FGFR1 axis, which acts redundantly with the PDGF/PDGFR axis. Under these conditions, a multiple kinase inhibitor such as TSU-68 may control fibroblast motility and growth in humans. Further understanding of the crosstalk between tumors and their microenvironments, including TAFs, may lead to development of more effective therapeutic modalities.

The microenvironment of MPM consists of various components, including endothelial cells, fibroblasts, immune cells, mesothelial cells, and extracellular matrix. In MPMs producing large quantities of VEGF, the interaction with endothelial cells seems to be particularly important. VEGF produced by MPM cells activates endothelial cells and induces angiogenesis, promoting tumor progression. ${ }^{12}$ In addition, VEGF activates endothelial cells and induces hypervascular permeability to produce pleural effusion. ${ }^{31}$ Therapy targeting VEGF/endothelial cells may therefore be effective for MPM cells that produce large (EHMES-10) but not small (MSTO-211H) quantities of VEGF. ${ }^{12}$ The results presented here suggest that therapy targeting TAFs and related molecules may be warranted for MPM with low VEGF expression and abundant TAFs, as in MSTO-211H cells.

The cytokine antibody array that we used is designed to scan for many cytokines at one time, but the array does 
not include PDGF-AA (see Supplemental Figure S2 at http://ajp.amjpathol.org); instead, the array detects PDGF-BB. However, we could not detect PDGF-BB in the supernatant of MSTO-211H cells when quantified by ELISA. Instead, a high level of PDGF-AA was detected by ELISA. This mismatch between cytokine antibody array and ELISA may have been due to the relatively lower specificity of the cytokine antibody array. In addition to HGF, low concentrations of CXCL5 have been observed in the supernatants of MRC- 5 but not MSTO-211H cells. CXCL5 (also known as epithelial-derived neutrophil-activating peptide 78, or ENA-78) was reported to be produced also by white blood cells, such as neutrophils and eosinophils, suggesting that CXCL5 may not be a specific fibroblast-derived cytokine that influences MPM function. Because the main issue under investigation in the present study was the interaction between MPM cells and fibroblasts, and the CXCL5 concentration in MRC-5 cells was much lower than that of HGF, we concentrated on HGF, which is produced abundantly by fibroblasts.

MPM is histologically classified into three types: epithelial, biphasic, and sarcomatous. Both cell lines used in the present study, MSTO-211H and EHMES-10, were established from patients with biphasic mesothelioma. However, these two cell lines show quite different characteristics, including different patterns of cytokine production and their content of TAFs in orthotopically implanted tumors. In addition, histological analyses of clinical specimens showed that the amount of TAFs did not correlate with MPM histological type. These findings suggest that histological differentiation and TAF accumulation in MPM may be regulated by different molecular mechanisms. We also detected simultaneous expression of FGF-2, PDGF-AA, and HGF in mesotheliomas with low numbers of TAFs, suggesting the need to analyze the role of these molecules in MPM tumors.

We have shown here that a malignant cytokine network between malignant pleural mesothelioma and tumor-associated fibroblasts, mediated through FGF-2, PDGF-AA, and HGF, exists in a population of MPM patients. Therefore, simultaneous inhibition of these three molecules may be clinically beneficial for patients with these tumors. Multiple targeted tyrosine kinase inhibitors may be appropriate for clinical trials of MPM patients, and treatments targeting the tumor microenvironment may also be beneficial in MPM.

\section{References}

1. Carbone M, Kratzke RA, Testa JR: The pathogenesis of mesothelioma. Semin Oncol 2002, 29:2-17

2. Robinson BW, Lake RA: Advances in malignant mesothelioma. N Engl J Med 2005, 353:1591-1603

3. Aisner $\mathrm{J}$ : Current approach to malignant mesothelioma of the pleura. Chest 1995, 107:332S-344S

4. Vogelzang NJ, Rusthoven JJ, Symanowski J, Denham C, Kaukel E, Ruffie P, Gatzemeier U, Boyer M, Emri S, Manegold C, Niyikiza C, Paoletti P: Phase III study of pemetrexed in combination with cisplatin versus cisplatin alone in patients with malignant pleural mesothelioma. J Clin Oncol 2003, 21:2636-2644

5. Bhowmick NA, Neilson EG, Moses HL: Stromal fibroblasts in cancer initiation and progression. Nature 2004, 432:332-337
6. McAllister SS, Gifford AM, Greiner AL, Kelleher SP, Saelzler MP, Ince TA, Reinhardt F, Harris LN, Hylander BL, Repasky EA, Weinberg RA: Systemic endocrine instigation of indolent tumor growth requires osteopontin. Cell 2008, 133:994-1005

7. Wang W, Li Q, Yamada T, Matsumoto K, Matsumoto I, Oda M, Watanabe G, Kayano Y, Nishioka Y, Sone S, Yano S: Crosstalk to stromal fibroblasts induces resistance of lung cancer to epidermal growth factor receptor tyrosine kinase inhibitors. Clin Cancer Res 2009, 15:6630-6638

8. Saltz LB, Clarke S, Díaz-Rubio E, Scheithauer W, Figer A, Wong R, Koski S, Lichinitser M, Yang TS, Rivera F, Couture F, Sirzén F, Cassidy $\mathrm{J}$ : Bevacizumab in combination with oxaliplatin-based chemotherapy as first-line therapy in metastatic colorectal cancer: a randomized phase III study. J Clin Oncol 2008, 26:2013-2019

9. Sandler A, Gray R, Perry MC, Brahmer J, Schiller JH, Dowlati A, Lilenbaum R, Johnson DH: Paclitaxel-carboplatin alone or with bevacizumab for non-small-cell lung cancer. N Engl J Med 2006, 355: 2542-2550

10. Araujo AM: Pemetrexed plus bevacizumab for second-line therapy of non-small-cell lung cancer: the importance of patient selection. J Clin Oncol 2010, 28:e131; author reply e132

11. Rosen LS, Gordon D, Tchekmedyian S, Yanagihara R, Hirsh V, Krzakowski M, Pawlicki M, de Souza P, Zheng M, Urbanowitz G, Reitsma $\mathrm{D}$, Seaman J: Zoledronic acid versus placebo in the treatment of skeletal metastases in patients with lung cancer and other solid tumors: a phase III, double-blind, randomized trial-the Zoledronic Acid Lung Cancer and Other Solid Tumors Study Group. J Clin Oncol 2003, 21:3150-3157

12. Li Q, Yano S, Ogino H, Wang W, Uehara H, Nishioka Y, Sone S: The therapeutic efficacy of anti vascular endothelial growth factor antibody, bevacizumab, and pemetrexed against orthotopically implanted human pleural mesothelioma cells in severe combined immunodeficient mice. Clin Cancer Res 2007, 13:5918-5925

13. Baglole CJ, Ray DM, Bernstein SH, Feldon SE, Smith TJ, Sime PJ, Phipps RP: More than structural cells, fibroblasts create and orchestrate the tumor microenvironment. Immunol Invest 2006, 35:297-325

14. Harvey P, Warn A, Newman P, Perry LJ, Ball RY, Warn RM: Immunoreactivity for hepatocyte growth factor/scatter factor and its receptor, met, in human lung carcinomas and malignant mesotheliomas. J Pathol 1996, 180:389-394

15. Kato S, Funakoshi H, Nakamura T, Kato M, Nakano I, Hirano A, Ohama E: Expression of hepatocyte growth factor and c-Met in the anterior horn cells of the spinal cord in the patients with amyotrophic lateral sclerosis (ALS): immunohistochemical studies on sporadic ALS and familial ALS with superoxide dismutase 1 gene mutation. Acta Neuropathol 2003, 106:112-120

16. Nakamura T, Sakai K, Matsumoto K: Anti-cancer approach with NK4: bivalent action and mechanisms. Anticancer Agents Med Chem 2010, 10:36-46

17. Albini A, Iwamoto Y, Kleinman HK, Martin GR, Aaronson SA, Kozlowski JM, McEwan RN: A rapid in vitro assay for quantitating the invasive potential of tumor cells. Cancer Res 1987, 47:3239-3245

18. Yano S, Wang W, Li Q, Matsumoto K, Sakurama H, Nakamura T, Ogino H, Kakiuchi S, Hanibuchi M, Nishioka Y, Uehara H, Mitsudomi $\mathrm{T}$, Yatabe $\mathrm{Y}$, Sone S: Hepatocyte growth factor induces gefitinib resistance of lung adenocarcinoma with epidermal growth factor receptor-activating mutations. Cancer Res 2008, 68:9479-9487

19. Nakataki E, Yano S, Matsumori $Y$, Goto H, Kakiuchi S, Muguruma H, Bando $\mathrm{Y}$, Uehara H, Hamada H, Kito K, Yokoyama A, Sone S: Novel orthotopic implantation model of human malignant pleural mesothelioma (EHMES-10 cells) highly expressing vascular endothelial growth factor and its receptor. Cancer Sci 2006, 97:183-191

20. Yamada T, Matsumoto K, Wang W, Li Q, Nishioka Y, Sekido Y, Sone S, Yano S: Hepatocyte growth factor reduces susceptibility to an irreversible epidermal growth factor receptor inhibitor in EGFRT790M mutant lung cancer. Clin Cancer Res 2010, 16:174-183

21. Nakamura T, Nishizawa T, Hagiya M, Seki T, Shimonishi M, Sugimura A, Tashiro K, Shimizu S: Molecular cloning and expression of human hepatocyte growth factor. Nature 1989, 342:440-443

22. Strizzi L, Vianale G, Catalano A, Muraro R, Mutti L, Procopio A: Basic fibroblast growth factor in mesothelioma pleural effusions: correlation with patient survival and angiogenesis. Int J Oncol 2001, 18:10931098 
23. Bertino P, Piccardi F, Porta C, Favoni R, Cilli M, Mutti L, Gaudino G: Imatinib mesylate enhances therapeutic effects of gemcitabine in human malignant mesothelioma xenografts. Clin Cancer Res 2008 14:541-548

24. Eagles G, Warn A, Ball RY, Baillie-Johnson H, Arakaki N, Daikuhara Y, Warn RM: Hepatocyte growth factor/scatter factor is present in most pleural effusion fluids from cancer patients. $\mathrm{Br} \mathrm{J}$ Cancer 1996, 73 377-381

25. Harvey P, Warn A, Dobbin S, Arakaki N, Daikuhara Y, Jaurand MC, Warn RM: Expression of HGF/SF in mesothelioma cell lines and its effects on cell motility, proliferation and morphology. $\mathrm{Br} \mathrm{J}$ Cancer 1998, 77:1052-1059

26. Burgess T, Coxon A, Meyer S, Sun J, Rex K, Tsuruda T, Chen Q, Ho SY, Li L, Kaufman S, McDorman K, Cattley RC, Elliott G, Zhang K, Feng X, Jia XC, Green L, Radinsky R, Kendall R: Fully human monoclonal antibodies to hepatocyte growth factor with therapeutic potential against hepatocyte growth factor/c-Met-dependent human tumors. Cancer Res 2006, 66:1721-1729

27. Previdi S, Maroni P, Matteucci E, Broggini M, Bendinelli P, Desiderio MA: Interaction between human-breast cancer metastasis and bone microenvironment through activated hepatocyte growth factor/Met and beta-catenin/Wnt pathways. Eur J Cancer 2010 46:1679-1691

28. Suzuki Y, Sakai K, Ueki J, Xu Q, Nakamura T, Shimada H, Matsumoto $\mathrm{K}$ : Inhibition of Met/HGF receptor and angiogenesis by NK4 leads to suppression of tumor growth and migration in malignant pleural mesothelioma. Int J Cancer 2010, 127:1948-1957

29. Porta C, Mutti L, Tassi G: Negative results of an Italian Group for Mesothelioma (G.I.Me.) pilot study of single-agent imatinib mesylate in malignant pleural mesothelioma. Cancer Chemother Pharmacol 2007, 59:149-150

30. Mathy A, Baas P, Dalesio O, van Zandwijk N: Limited efficacy of imatinib mesylate in malignant mesothelioma: a phase II trial. Lung Cancer 2005, 50:83-86

31. Yano S, Shinohara $H$, Herbst RS, Kuniyasu H, Bucana CD, Ellis LM, Fidler IJ: Production of experimental malignant pleural effusions is dependent on invasion of the pleura and expression of vascular endothelial growth factor/vascular permeability factor by human lung cancer cells. Am J Pathol 2000, 157:1893-1903 